\title{
Hatching Induction of Cyst Nematodes in Bare Soils Drenched With Root Exudates Under Controlled Conditions
}

\author{
Bruno Ngala1 ${ }^{1}$ Nicolas Mariette ${ }^{2}$, Mélina lanszen ${ }^{1}$, Pauline Dewaegeneire $^{1}$, \\ Marie-Christine Denis ${ }^{2}$, Catherine Porte ${ }^{2}$, Christophe Piriou², Emilie Robilliard ${ }^{3}$, \\ Antoine Couetili ${ }^{3}$, Eric Nguema-Ona ${ }^{4}$, Jean-Claude Yvin ${ }^{4}$, Virginie Gobert', \\ Amélie Beury ${ }^{1}$, Anne-Claire Le Roux ${ }^{5}$, Josselin Montarry ${ }^{2}$ and Sylvain Fournet ${ }^{2 *}$ \\ ${ }^{1}$ FN3PT/inov3PT, Rue des Champs Potez, Achicourt, France, ${ }^{2}$ IGEPP, INRAE, Institut Agro, Univ Rennes, Le Rheu, France, \\ ${ }^{3}$ Société d'Investissement Légumière et maraîchère de Basse Normandie (SILEBAN), Gatteville le Phare, France, ${ }^{4}$ Centre \\ Mondial de l'Innovation-Roullier, Laboratoire de Nutrition Végétale, Pôle Stress Biotiques, Saint Malo, France, \\ ${ }^{5}$ FN3PT/inov3PT, INRAE-IGEPP, Le Rheu, France
}

OPEN ACCESS

Edited by:

Shahid Siddique,

University of California, Davis,

United States

Reviewed by:

Holger Heuer,

Julius Kühn-Institut, Germany

Sebastian Kiewnick,

Julius Kühn-Institut -

Bundesforschungsinstitut für

Kulturpflanzen, Germany

${ }^{*}$ Correspondence:

Sylvain Fournet

sylvain.fournet@inrae.fr

Specialty section:

This article was submitted to

Plant Pathogen Interactions,

a section of the journal

Frontiers in Plant Science

Received: 04 September 2020 Accepted: 30 November 2020

Published: 08 January 2021

Citation:

Ngala B, Mariette $N$, lanszen $M$, Dewaegeneire P, Denis M-C, Porte $C$,

Piriou $C$, Robilliard E, Couetil A,

Nguema-Ona E, Yvin J-C, Gobert V,

Beury A, Le Roux A-C, Montarry J

and Fournet $S$ (2021) Hatching

Induction of Cyst Nematodes in Bare

Soils Drenched With Root Exudates

Under Controlled Conditions.

Front. Plant Sci. 11:602825.

doi: 10.3389/fpls.2020.602825
Cyst nematodes account for substantial annual yield losses in crop production worldwide. Concerns over environmental and health issues due to the use of chemical nematicides mean alternative sustainable and integrated solutions are urgently required. Hatch induction of encysted eggs in the absence of host plants, i.e., 'suicide-hatching,' could be a sustainable alternative in reducing population densities of cyst nematodes in infested soils. Here we examined in situ hatching of encysted eggs of Globodera pallida, Heterodera carotae, and Heterodera schachtii at varying soil depths, following exogenous applications of host root exudates in repeated glasshouse experiments. Cysts were retrieved 30 or 43 days post-incubation depending on the nematode species and assessed for hatching rates relative to the initial number of viable eggs per cyst. Hatching of the potato cyst nematode $G$. pallida depended on both soil moisture and effective exposure to root exudates, and to a lesser extent on exudate concentration. The carrot cyst nematode $H$. carotae had over $75 \%$ hatched induced by root exudate irrespective of the concentration, with better hatch induction at $20 \mathrm{~cm}$ as compared with $10 \mathrm{~cm}$ soil depth. Hatching of the beet cyst nematode $\mathrm{H}$. schachtii largely depended on the soil moisture level at constant temperature, rather than the type or concentration of root exudates applied. As a conclusion, exogenously applied host root exudates may play a major role in inducing in situ hatch of encysted eggs of potato and carrot cyst nematodes in the absence of host plant under favorable soil temperature/moisture conditions. To improve such strategy, the characterization of chemical profiles of the root exudate composition and field validation are currently ongoing.

Keywords: Globodera, Heterodera, in vitro, in situ, hatching, soil depth, encysted eggs, root exudates

\section{INTRODUCTION}

Cyst nematodes are sedentary root endo-parasites of many plants, causing stunted growth and wilt on their hosts. They are associated with serious damages to a broad range of crops amongst which include potatoes, carrots, beets, brassicas and cereals. These organisms represent a major threat in agriculture, especially species belonging to the genera Globodera and Heterodera which are among 
the most devastating crop pests worldwide (Jones et al., 2013). The economic losses associated with cyst nematodes are difficult to estimate. An annual figure of $9 \%$ worldwide have been estimated for potato cyst nematodes (PCN) for total potato production (Turner and Subbotin, 2013). Annual excesses of US\$1.5 billion have been estimated for soybean cyst nematode in the United States alone (Chen et al., 2001), while cereal cyst nematodes may sometimes exceed $90 \%$ yield lost depending on environmental conditions (Nicol et al., 2011).

Effective management of cyst nematodes at a field scale is very challenging considering their soil borne nature coupled with their high survival abilities in the absence of the host plant (Marks and Brodie, 1998). The cyst, which corresponds to the desiccated body of the dead female, can contain hundreds of eggs protected against environmental extremes. Infective juvenile (J2) in their dormant state are contained within encysted eggs and can remain viable for several years (Evans and Stone, 1977), making these pests particularly difficult to eradicate once established in the field (Bairwa et al., 2017). The requirements for more environmentally friendly control methods has led to the ban of the broad-spectrum soil fumigant, methyl bromide in 2005, which used to be a silver bullet against soil borne plant parasitic nematodes and complete phase out from use in developing countries in 2015. Hence, there is an urgent need to develop new effective management strategies.

Upon hatch, infective second stage juveniles (J2) are vulnerable and can only navigate through a limited distance, as they depends entirely on their lipid reserves to locate a suitable host to invade and start feeding (Storey, 1984). In potato cyst nematodes, Robinson et al. (1987) noticed that hatched J2 could not survive for more than 2 weeks. This vulnerability is usually offset in some groups of cyst nematode with a sophisticated synchronization of hatching with the presence of signals from the host root exudates (Masler and Perry, 2018). These hostspecific compounds collectively referred to as hatching factors include glycoalkaloids or terpenes such as the Glycinoeclepins in root exudates of kidney beans, responsible for hatch induction of Heterodera glycines (Masamune et al., 1982; Fukuzawa et al., 1985a,b). Discrepancies in the hatching response to host root exudates exist among cyst nematodes and have been nicely categorized into four broad groups by Perry (2002). In general, this synchronization is very strict for species with a narrow host range, such as Globodera spp., which are restricted to members of the Solanaceae (Subbotin et al., 2010), and Heterodera carotae which is restricted to the genera Daucus and Torilis (Aubert, 1986). By contrast, species like Heterodera schachtii, which have a wide host range tend to be less dependent on host root exudates. For the latter, in vitro hatching of juveniles can be induced with the presence of water only, although hatching is, however, enhanced in the presence of host root exudates (Masler and Perry, 2018).

Here the idea was thus to exploit the vulnerability of hatched $\mathrm{J} 2$ and the specificity of hatching factors to develop a control strategy based on the artificial induction of hatching using natural extracts in the absence of the host plant. This strategy, called 'suicide hatching' will thus lead to the death of newly hatched J2 and to the reduction of population levels in the soil (Devine and Jones, 2000; Kushida et al., 2003). This is not a new idea and even less a new strategy. Indeed in vitro experiments have already demonstrated high levels of hatching in some cyst nematodes, induced by host root exudates produced in laboratory (Mugniéry and Bossis, 1988; Scholte, 2000). Devine and Jones (2001) also reported significant induction of 'suicide hatching' on field population of Globodera rostochiensis by the incorporation of tomato root exudates in the soil. Their report also indicated that successful application of the 'suicide hatching' technique was dependent on soil type, with best results achieved on sandy soils unlike clay and peaty soils. These observations demonstrated the potential of 'suicide hatching' in a sustainable management of cyst nematodes but, despite these promising results, this strategy is still not operational in natural conditions. There have been some advances in the development of tools needed for the characterization of the chemical profiles of hatching factors.

This study thus aimed at: (i) screening a large range of wild or cultivated reference host plants previously reported with satisfactory results of hatching induction, (ii) determine the optimal doses and exposure times that induce the highest hatching in vitro and (iii) confirm the efficiency of this control strategy in soil experiments according to the applied doses and soil depth. Three cyst nematode species, G. pallida, $H$. carotae, and $H$. schachtii, characterized by different ecological requirements and host ranges were tested.

\section{MATERIALS AND METHODS}

\section{Nematode Species}

Three cyst nematode species were used in these experiments and include the potato cyst nematode (PCN) G. pallida, the carrot cyst nematode (CCN) H. carotae, and the beet cyst nematode (BCN) H. schachtii. The cyst population for each nematode species was from the same generation produced in glasshouse between 2016 and 2018 , and stored at $4^{\circ} \mathrm{C}$ after extraction for minimum of $3-$ 9 months to break obligate diapause prior to use in experiments. Cyst sizes selected for the experiment ranged from 300 to $450 \mu \mathrm{m}$ in diameter with special attention to physical damage, thus, all broken or cysts with cracks were discarded.

\section{Root Exudates Production}

The production of root exudates from non-tuberous species was performed by soil leaching according to the protocol described by Widdowson and Wiltshire (1958) with some modifications. Seeds were sawn on cell seedling trays and placed in glasshouse regulated at $21 / 17^{\circ} \mathrm{C}$ day/night temperatures, respectively, with a photoperiod of $16 \mathrm{~h}$ over 2 weeks to attain the four-leaf stage. Seedlings were then transplanted into individual pots filled with $1 \mathrm{~L}$ of sterile soil. The collection of root exudates began 2 weeks post-transplanting and continued at a weekly interval upto week-six. At each time of root exudates collection, plant pots were allowed for $24 \mathrm{~h}$ without application of water before being saturated by slowly pouring tap water from the top of the pot. Following pot saturation (water holding capacity), the pots were each suspended on a $1 \mathrm{~L}$ beaker before $100 \mathrm{ml}$ of tap water was added from the top of the pot and allowed over $30 \mathrm{~min}$ to leach into the beaker underneath the pot. After $30 \mathrm{~min}$, an additional 
$100 \mathrm{ml}$ of tap water was added to the pot and allowed for a further $30 \mathrm{~min}$ before the content of the beaker $(200 \mathrm{ml})$ was retrieved. For each plant species, root exudates collected at the different times were pooled.

Unlike with seeds, to produce root exudates from tuberous species, tubers previously sprouted over 14 days at $21^{\circ} \mathrm{C}$ in the dark were suspended on tap water in plastic boxes such that the distance between the tubers and water was approximately $0.5 \mathrm{~cm}$. The close proximity of tubers to water meant that roots produced by the tubers were immediately immersed in water. The setup was placed in the dark at $20^{\circ} \mathrm{C}\left( \pm 0.5^{\circ} \mathrm{C}\right)$ and monitored over 21 days, before the water was collected and adjusted such that one tuber was equivalent to $250 \mathrm{ml}$.

Each batch of root exudates obtained for each species was homogenized and filtrated through cellulose filters of $0.2 \mu \mathrm{m}$ pore sizes before storage at $-20^{\circ} \mathrm{C}$ until required for the experiments.

\section{Selection and Screening of Root Exudates}

In order to select the most efficient root exudates for each nematode species, a wide range of cultivated plants or wild related members of the same family able to induce hatching of each nematode species were selected based on both their host status and phylogenetic criteria following previous reports such as the studies by Evans (1983); Mugniéry and Bossis (1988), Franco et al. (1999), or Scholte (2000). In addition, some non-host plants or plants with an unknown host status, but phylogenetically related to the host plants were also selected. Overall, 120 species/cultivars, both wild and cultivated plants, were selected for the three cyst nematode species with, respectively, 62 for G. pallida 26 for $H$. schachtii and 32 for $H$. carotae. Seeds were obtained from different European Biological Resource Centers and seed sailors.

The ability of root exudates to induce hatching of encysted eggs of G. pallida, H. carotae, and $H$. schachtii was evaluated in vitro with the aid of 24-well plastic plates. For each set of root exudates, one cyst, representing an individual replicate, was deposited on an adapted $250 \mu \mathrm{m}$ sieve (Ngala et al., 2014) placed in individual wells. The sieve allowed active passage of hatched juveniles, while enabling the easy transfer of the cyst to new/refreshed hatching solution. One $\mathrm{ml}$ of the test root exudate, adjusted to $45 \%$ of the crude exudates, was then added in each well and plates were incubated in the dark at $20^{\circ} \mathrm{C}\left( \pm 0.5^{\circ} \mathrm{C}\right)$, with each treatment consisting of 12 replicates (i.e., 12 cysts). The number of hatched juveniles were scored at days $1^{1}, 2,4,10,15$, and 30 days. At each time of assessment, the sieves with the cyst were rinsed and transferred into new wells containing fresh root exudates. At the end of the experiments, individual cysts were opened to count the number of unhatched viable and non-viable eggs/juveniles in a bid to compute hatching rate (as a proportion of the viable eggs).

Following the screening, two most efficient root exudates were selected for each nematode species based on their level of hatch activation and the speed of hatching when the tested nematode species were exposed to the respective root exudates. In addition

\footnotetext{
${ }^{1}$ Assessments conducted on H. schachtii only due to it fast rate of hatching.
}

to rate of hatch induction, the ease of obtaining the cultivars and the production of root exudates played a central role in the selection process.

\section{Dose and Exposure Time Experiments}

To determine the optimum concentrations of root exudates able to activate maximum hatch of cyst nematodes, in vitro hatching experiments were set-up with the root exudates selected in the screening assays for G. pallida. The root exudates selected included Solanum tuberosum cv. Désirée and Iodéa each diluted to $10,25,45$, and $70 \%$ of the crude exudates as compared with tap water $(0 \%)$. The experiment was conducted following the same protocol used for the screening of the root exudates with the exception that the assessments for hatched juveniles was done at $4,7,9,11,15$, and 30 days post-incubation. Each test exudate or concentration had six replicates. Preliminary experiments with $H$. carotae and $H$. schachtii revealed that exudate concentration was not an important factor, thus it was not necessary to conduct the concentration test on these cyst nematode species.

To determine the exposure time necessary between root exudates and encysted eggs of cyst nematodes to induce a maximum hatching, in vitro hatching experiments were set-up in 24-well plastic plates as described above for the determination of optimum concentration. The different exposure time tested included $0,4,7,9,11,15$, and 30 days for G. pallida, and 0,1 , $2,4,10,15$, and 30 days for $H$. carotae and $H$. schachtii, with the concentration of root exudates in both cases adjusted to $30 \%$ of the crude root exudates. Therefore, assessments for hatched J2 were conducted at the stated exposure times, during which, cysts were either transferred into water after their respective time of exposure with root exudates, or the solution was refreshed if the end of the exposure time of the cysts with the hatching solution had not finished. Each test exudate or concentration had six replicates.

To determine whether a continuous exposure was needed to induce a maximum hatching, cysts were periodically exposed to root exudates for $4 \mathrm{~h}$ every 6 days before re-deposition into tap water. A positive control consisted of a treatment with continuous exposure between root exudates and cysts, while a negative control (continuous exposure with water) were added for each nematode species. The test root exudates were diluted to $85 \%$ for H. schachtii and $45 \%$ for G. pallida and H. carotae. All treatments had six replicates.

\section{Root Exudates Efficiency Under Soil Conditions}

These experiments were conducted in 2018 and 2019 under controlled environmental conditions $\left(20 / 16^{\circ} \mathrm{C}\right.$ day/night temperatures, respectively, with a photoperiod of $16 \mathrm{~h}$ ) at three different sites depending on the nematode species. Samples of soils used in all experiments were sent to Centre Mondial d'Innovation (CMI) Groupe-Roullier, St-Malo, France for texture and $\mathrm{pH}$ analysis.

All experiments except experiments with $H$. schachtii were conducted in plastic pots $(35 \mathrm{~cm}$ height $-8 \mathrm{~cm}$ diameter) under controlled conditions, filled with natural field soils free from any 
cyst nematode species. Smaller plastic pots $\left(8 \mathrm{~cm}^{*} 8 \mathrm{~cm}^{*} 8 \mathrm{~cm}\right)$ were used in experiments with $H$. schachtii.

In all experiments, each set of pot experiments was arranged in a randomized complete block design with each treatment having ten replicates. The soil moisture was maintained around $80 \%$ of field capacity throughout the period of test. Therefore, prior to each application of treatment or water, the moisture content of the soils was recorded to determine the amount of water loss. This lose was then compensated by the prior application of tap water to the respective pots with water deficit where applicable to attain $80 \%$ of the field capacity.

For the three nematode species, the initial number of encysted viable eggs $\left(P_{i}\right)$ was estimated from $10 \times 10$ cysts. Therefore, 10 cysts from same population measuring between 300 and $450 \mu \mathrm{m}$ were randomly picked and placed onto a tiny droplet of tap water on a piece of aluminum block and crushed with the aid of a glass slide. The crushed cysts/eggs mixture was rinsed into an $80 \mathrm{~mL}$ Pyrex beaker, vigorously homogenized to separate egg clusters and suspended into $40 \mathrm{~mL}$ tap water. The suspension was homogenized before aliquots of $3 \mathrm{~mL} \times 1 \mathrm{~mL}$ were pulled with a $2 \mathrm{~mL}$ glass pipette onto $1 \mathrm{~mL}$ nematode counting slide for the quantification of viable and non-viable J2 to determine the initial viable eggs per cyst $\left(P_{i}\right)$.

At the end of the experiments, to count the remaining (unhatched) viable J2 per cyst $\left(P_{f}\right)$ and determine the hatching rate for each treatment, the incubated cyst sachets were retrieved and numbered according to levels, before being arranged into appropriately labeled petri-dishes according to treatment on each block. Each sachet was carefully cut open with a pair of scissors and the cysts were carefully retrieved. The number of viable and non-viable eggs/cyst was then estimated as described above for $P_{i}$ assessments. The hatching percentage for each treatment was then computed as the ratio of difference between the mean $P_{i}$ and $P_{f}$ values to the mean $P_{i}$ value $\left(\left[\left(P_{i}-P_{f}\right) / P_{i}\right]\right)$ and expressed as percentages.

Experiments with G. pallida were conducted in 2018 at FN3PT/inov3PT (Achicourt, France) and INRAE (Le Rheu, France) laboratories with soils collected from Laon and La Gruche, respectively, and repeated in 2019 only in FN3PT/inov3PT. Soils were pre-moistened at 45 to $50 \%$ of field capacity prior to filling into experimental pots to the $30 \mathrm{~cm}$ level. In 2018, treatments included Désirée root exudates at $25 \%$ or $45 \%$ dilutions of the crude root exudates, with tap water as control. In the repeated experiments in 2019, exudates were further diluted to $5 \%$ while maintaining $25 \%$ of the crude root exudates with the addition of Iodéa root exudates to the treatment list. Each pot was inoculated with three sachets each containing 10 cysts placed at 5 , 15 , and $25 \mathrm{~cm}$ from top soil. The mesh allowed the movement of hatched $\mathrm{J} 2$ from the cysts to the soil. Experimental pots each received $60 \mathrm{ml}$ of the test root exudates at their respective concentrations or tap water at a 4 days interval over the first 16 days ( 5 applications). Soil moisture was then maintained with tap water only until the end of the experiments (43 days).

Experiments with $H$. carotae were conducted at the SILEBAN laboratories (Gatteville-le-Phare, France). The soil used for the experiments was collected from a single field (Gatteville-le-Phare, France). Pots were filled with soil as describe above for G. pallida and inoculated with two sachets each containing 15 cysts at 10 and $20 \mathrm{~cm}$ depth from top soil. Treatments for these experiments included carrot cv. Touchon or cv. Pusar Kesar, as crude exudates or at $50 \%$ dilution, with tap water as a control. Each pot received $50 \mathrm{ml}$ of the respective treatments or tap water at a 4-days interval for the first 20 days (six applications). We then maintained the moisture content with tap water only until the end of the experiments (40 days).

Experiments with $H$. schachtii were conducted at the INRAE laboratories (Le Rheu, France), with the same soil used in the experiments with G. pallida. Treatments for these experiments included undiluted root exudates of sugar beet cv. Acacia or tap water as control. Pots were inoculated with one sachet only, at $4 \mathrm{~cm}$ depth from top soil, containing 10 cysts for each replicated treatment. For treatment with root exudates, two application regimes (R) were employed, which included an amount of 15 or $30 \mathrm{ml}$ of undiluted root exudates every 2 (R1) or 4 (R2) days, respectively, during the first 16 days. We then maintained the moisture content with $30 \mathrm{ml}$ of tap water until the end of the experiments (30 days).

\section{Statistical Analysis}

All data was checked for normality of residuals with the aid of the residual and mean plots. Data for pot experiments were subjected to a general analysis of variance (ANOVA) specifically the general treatment structure in randomized blocks using GenStat ${ }^{\circledR}$ 19th Edition software pack (VSNI Products, United Kingdom). Significant differences between treatments and controls were determined using Tukey's multiple range test (5\% significance level). For dose and exposure time experiments, the relationship with the percentage of hatched eggs per cyst was explored using linear and quadratic models. The model selection based on Akaike's information criteria, AIC (Johnson and Omland, 2004), was used in order to determine the model of best fit. Linear regression was therefore, performed on exposure time experiments to observe the relationship with the rate of hatch for each cyst nematode species, while quadratic models were used to explain dose effect on rate of hatching for G. pallida.

\section{RESULTS}

\section{Root Exudates Screening Experiments}

Root exudates collected from 66 plants and/or varieties were screened for G. pallida hatch induction: 62 specifically selected for this species and two root exudates each initially selected for $H$. carotae and H. schachtii (Table 1A), respectively. High levels of hatch induction was observed for root exudates of some solanaceous plants, with the top five including Solanum tuberosum cv. Iodéa \& Magnum, S. gourlayi, S. tuberosum cv. Désirée, and S. melongena cv. Listada de Gandia, in this order, which accounted for $75-95 \%$ hatch induction after an incubation period of 30 days (Table 1A). The hatching rate was faster for root exudates of some potato varieties such as Iodéa, Magnum, Blanche as well as tomato cv. Saint-Pierre in which between 41 and $79 \%$ hatch was observed just after 10 days exposure of encysted eggs of G. pallida to the root 
TABLE 1A | Plant species and/or cultivars screened for the ability of their root exudates to induce hatching of Globodera pallida in vitro.

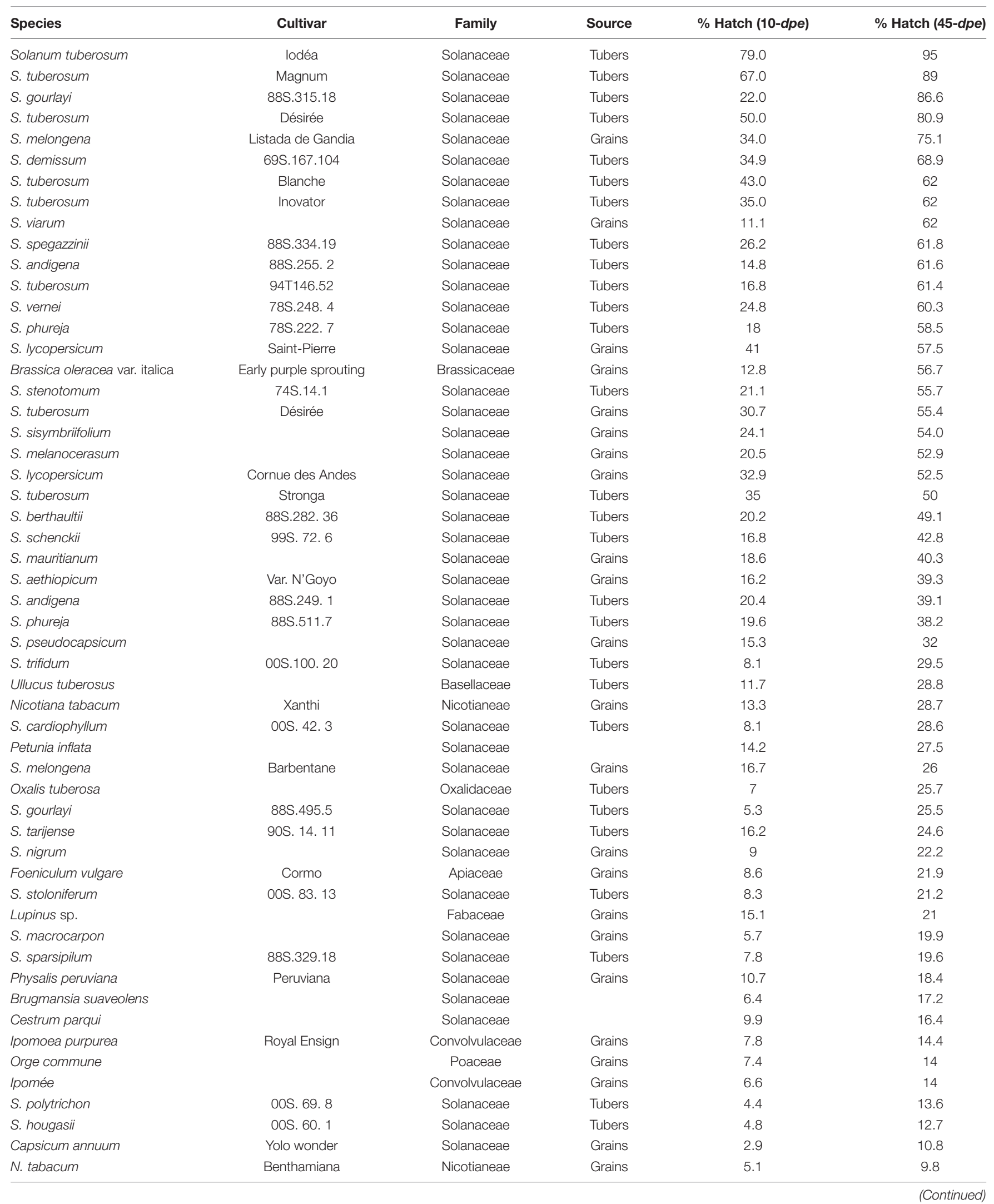


TABLE 1A | Continued

\begin{tabular}{|c|c|c|c|c|c|}
\hline Species & Cultivar & Family & Source & $\%$ Hatch (10-dpe) & $\%$ Hatch (45-dpe) \\
\hline S. stenotomum & 74S. 16. 3 & Solanaceae & Tubers & 3 & 9.2 \\
\hline Datura stramonium & & Solanaceae & Grains & 3.4 & 9 \\
\hline B. juncea & Aurea & Brassicaceae & Grains & 1.9 & 7.3 \\
\hline D. carota & Western red & Apiaceae & Grains & 0.6 & 6.2 \\
\hline lochroma australe & & Solanaceae & & 1.6 & 5.4 \\
\hline Ipomoea batatas & & Convolvulaceae & Tubers & 0 & 4.7 \\
\hline Petunia integrifolia & & Solanaceae & Grains & 1.7 & 4.1 \\
\hline C. annuum & Cayenne & Solanaceae & Grains & 1.6 & 3.9 \\
\hline C. annuum & Belrubi & Solanaceae & Grains & 0 & 1 \\
\hline Tropaeolum tuberosum & & Tropaeolaceae & Tubers & 0.3 & 0.7 \\
\hline
\end{tabular}

exudates (Table 1A). Although the percentage hatch of G. pallida was generally low in root exudates of non-solanaceous plant species, $(<30 \%)$, some solanaceous plants also induced very low hatch (Table 1A). Surprisingly, 56\% hatch was observed in root exudates of Brassica oleracea cv. 'Early Sprouting, a nonsolanaceous plant.

Root exudates collected from 34 plants were screened for $H$. carotae, with 32 specifically selected for this species and one each initially selected for G. pallida and $H$. schachtii, respectively. Results (Table 1B) highlighted two distinct group of plants: the first group induced hatching of $20 \%$ and above, and included wild or cultivated carrot varieties and species, whereas the second group had less than $1 \%$ hatch induction, and included plants not belonging to the carrot's family. Among the exudates of the first group, three induced hatching of $70 \%$ and above, especially the carrots cv. Touchon and Pusa Kesar (Table 1B).

Root exudates collected from 30 plants were screened for H. schachtii, with 26 belonging to the Brassicaceae (host family), and two each initially selected for G. pallida and $H$. carotae (Table 1C). Plants belonging to the host range induced high hatching levels (above 80\%) after 30 days exposure. Sugar beets cv. Julietta and Acacia were notably the most efficient, inducing $100 \%$ hatch in vitro. The rate of hatch was faster in root exudates from species such as Brassica carinata cv. Aurea and B. oleracea cv. Early sprouting (Table 1C).

Following results from the screening, Solanum tuberosum cv. Iodéa and Désirée were selected for G. pallida, while Daucus carota cv. Touchon and cv. Pusa Kesar were selected for H. carotae and Beta vulgaris cv. Acacia and was selected for H. schachtii (Table 1).

\section{Dose and Exposure Time Experiments}

For the dose effect, the quadratic model fitted best for the data, for the test root exudates (Désirée an Iodéa). Dose dependent hatch induction of $G$. pallida showed an optimum performance at $45 \%$ concentration of root exudates for potato $\mathrm{cv}$. Iodéa. Globodera pallida hatch induction by potato cv. Désirée root exudates increase to a peak of $25 \%$, before stabilizing from 25 to $70 \%$ concentration (Figure 1). Generally, hatching of G. pallida was positively correlated with concentration of Iodéa $\left(R^{2}=0.975\right.$; $P=0.025)$ up to $45 \%$ concentrations, beyond which the rate of hatching draped. Similarly, Désirée root exudates showed positive relationship with $G$. pallida hatching $\left(R^{2}=0.950 ; P=0.047\right)$ up to a peak of $25 \%$ with further increase in dose having no additional effect on $\%$ hatch (Figure 1).

A periodic exposure for $4 \mathrm{~h}$ every 6 days induced similar hatching rates in the three species as a continuous exposure to root exudates (Table 2). Linear regression analysis revealed that the exposure time between root exudates and encysted eggs necessary to induce significant levels of hatch was an important factor for G. pallida and $H$. carotae, but not for $H$. schachtii (Figure 2). Generally, 11 days exposure to Désirée root exudates was necessary to induce a significant $\left(R^{2}=0.632 ; P<0.001\right)$ amount of hatching of $G$. pallida, with an optimum hatch at 15 days of incubation (Figure 2A). Heterodera carotae needed a minimum of 4 days exposure to root exudates for a significant induction $\left(R^{2}=0.790 ; P<0.001\right)$ hatch, with an optimum exposure time of 30 days (Figure 2B). However, $H$. schachtii had a similar level of hatching in water and root exudates, with a weak and non-significant $\left(R^{2}=0.325 ; P=0.088\right)$ relationship with exposure time under in vitro conditions (Figure 2C).

\section{Root Exudates Efficiency Under Soil Conditions}

An analysis for the particle size distribution of the soils used for the pot experiments revealed that the soil texture was more or less sandy with a fairly neutral $\mathrm{pH}$ (Table 3 ).

\section{Hatching of Globodera pallida in Soil}

Soil experiments conducted on G. pallida in 2018 revealed a significant increase of hatching $(>70 \%)$ following potato $\mathrm{cv}$. Désirée root exudate as compared with tap water applications $(<40 \%)\left(F_{2,27}=24.49 ; P<0.001\right.$ at $5 \mathrm{~cm}, F_{2,27}=32.2 ; P<0.001$ at $15 \mathrm{~cm}$ and $F_{2,27}=29.2 ; P<0.001$ at $25 \mathrm{~cm}$; Figure 3A). However, there was no significant dose effect on the hatching rate with exudates diluted to 25 or $45 \%$. There was also no significant depth effect on the rate of hatching for all concentrations of root exudates tested. Results obtained in 2018 were partially confirmed in the repeated experiments in 2019, but there were no significant differences at $25 \mathrm{~cm}$ soil depth $\left(F_{4,45}=1.872\right.$; $P=0.132$; Figure 3B). For cysts placed at 5 and $15 \mathrm{~cm}$ soil depth, hatching was significantly higher than the control (tap water) for pots drenched with Désirée and Iodéa root exudates $\left(F_{4,45}=9.524 ; P<0.001\right.$ at $5 \mathrm{~cm}$ and $F_{4}, 45=7.916 ; P<0.001$ 
TABLE 1B | Plant species and/or cultivars screened for the ability of their root exudates to induce hatching of Heterodera carotae in vitro.

\begin{tabular}{|c|c|c|c|c|c|}
\hline Species & Cultivar & Family & Source & $\%$ Hatch (10-dpe) & $\%$ Hatch (30-dpe) \\
\hline D. carota & Touchon & Apiaceae & Seed & 8 & 84.3 \\
\hline D. c. carota ssp. maximus & & Apiaceae & Seed & 11.7 & 72.8 \\
\hline D. carota & Puska kaesar & Apiaceae & Seed & 27 & 69.6 \\
\hline D. carota & Western red & Apiaceae & Seed & 14.3 & 63.9 \\
\hline D. c. carota ssp. carota var. carota & & Apiaceae & Seed & 3 & 63.3 \\
\hline D. c. gummifer ssp. gummifer var. gummifer & & Apiaceae & Seed & 20.4 & 58 \\
\hline D. c. gummifer ssp. drepanensis & & Apiaceae & Seed & 2.2 & 55.2 \\
\hline D. carota & Haian-3-sun & Apiaceae & Seed & 9.6 & 54.3 \\
\hline D. carota & Nantaise & Apiaceae & Seed & 5.6 & 52.4 \\
\hline D. c. intermediaire & & Apiaceae & Seed & 2.8 & 48.5 \\
\hline D. c. gummifer ssp. hispidus & & Apiaceae & Seed & 2 & 42.2 \\
\hline D. carotae & $\mathrm{T} 16$ & Apiaceae & Seed & 2.6 & 40.9 \\
\hline D. c. gummifer ssp. hispanicus 684 & & Apiaceae & Seed & 3.7 & 40.9 \\
\hline D. carota & Muscade d'Alger & Apiaceae & Seed & 8.5 & 36.8 \\
\hline D. c. gummifer ssp. commutatus & & Apiaceae & Seed & 3 & 33.2 \\
\hline D. c. carota ssp. maritimus & & Apiaceae & Seed & 2.2 & 33 \\
\hline D. carota & Violette turque & Apiaceae & Seed & 14.3 & 31 \\
\hline D. c. carota ssp. gadecaei & & Apiaceae & Seed & 3 & 25.4 \\
\hline D. carota & Jaune du Doubs & Apiaceae & Seed & 1.7 & 20.9 \\
\hline D. capillifolius & & Apiaceae & Seed & 0.7 & 20.7 \\
\hline Petroselinum crispum & & Apiaceae & Seed & 0.4 & 0.6 \\
\hline P. c. ssp. tuberosum & & Apiaceae & Seed & 0,0 & 0.6 \\
\hline Pastinaca sativa & & Apiaceae & Seed & 0.2 & 0.2 \\
\hline Apium graveolens var. rapaceum & & Apiaceae & Seed & 0.2 & 0.2 \\
\hline Foeniculum vulgare & "Finale" & Apiaceae & Seed & 0.0 & 0.2 \\
\hline Anthriscus cerefolium & & Apiaceae & Seed & 0.0 & 0.2 \\
\hline F. vulgare & "Cormo" & Apiaceae & Seed & 0.2 & 0.2 \\
\hline Beta vulgaris & Julietta & Amaranthaceae & Seed & 0.2 & 0.2 \\
\hline Anethum graveolens & & Apiaceae & Seed & 0.0 & 0.0 \\
\hline Anthriscus cerefolium crispum & & Apiaceae & Seed & 0.0 & 0.0 \\
\hline Conium maculatum & & Apiaceae & Seed & 0.0 & 0.0 \\
\hline Coriandrum sativum & & Apiaceae & Seed & 0.0 & 0.0 \\
\hline Apium graveolens & & Apiaceae & Seed & 0.0 & 0.0 \\
\hline S. tuberosum & '94T146.52' & Solanaceae & Seed & 0.0 & 0.0 \\
\hline
\end{tabular}

at $15 \mathrm{~cm}$; Figure $3 \mathbf{B}$ ). Whatever the root exudate (Désirée and Iodéa), hatching was higher at $25 \%$ as compared with $5 \%$ concentration of root exudates. In line with some observations in 2018, cyst incubated within the top $15 \mathrm{~cm}$ soil depth in 2019 experiments had an increase in level of in situ hatch as compared with hatching at $25 \mathrm{~cm}$ soil depth for G. pallida.

\section{Hatching of Heterodera carotae and $H$. schachtii in Soil}

The general average hatch of $H$. carotae in soil drenched with root exudates of Daucus carota cv. Pusa Kesar or carrot Touchon was approximately $70 \%$ irrespective of the concentration of the root exudates, whereas in soil drenched with tap water, the hatching level was approximately $40 \%$ (Figure 4). At $20 \mathrm{~cm}$ soil depth, there was approximately a 15\% improvement in hatching when compared with hatching of encysted eggs placed at $10 \mathrm{~cm}$ soil depth for all treatments with root exudates, irrespective of concentration. Significant differences between treatments and control were observed at $20 \mathrm{~cm}\left(F_{4,45}=7.363 ; P<0.001\right)$ but not at $10 \mathrm{~cm}\left(F_{4}, 45=2.018 ; P=0.108\right)$ soil depth (Figure 4$)$.

H. schachtii performed well in pots drenched with tap water, inducing over $60 \%$ hatch, which was further significantly enhanced in pots drenched with undiluted sugar beet root exudates $\left(F_{2,27}=15.94 ; P<0.001\right.$; Figure 5).

\section{DISCUSSION}

The main objective of this study was to evaluate the feasibility of the management of the three cyst nematode species, G. pallida, $H$. carotae, and $H$. schachtii using naturally produced root exudates. This study has provided some new and sometime surprising insights into the hatching behavior such as induction time, hatching dynamics and soil depth effects for the three studied cyst nematode species. Under the framework of optimizing the 'suicide hatching' strategy with natural plant secretions, this study enabled the development facilities for 
TABLE 1C | Plant species and/or cultivars screened for the ability of their root exudates to induce hatching of Heterodera schachtii in vitro.

\begin{tabular}{|c|c|c|c|c|c|}
\hline Species & Cultivar & Family & Source & $\%$ Hatch (2-dpe) & $\%$ Hatch (30-dpe) \\
\hline Beta vulgaris & Julietta & Amaranthaceae & Seed & 63.8 & 100 \\
\hline Beta vulgaris & Acacia & Amaranthaceae & Seed & 56.9 & 100 \\
\hline Brassica oleracea var. botrytis & Snowball & Brassicaceae & Seed & 68.7 & 100 \\
\hline B. napus & Yudal & Brassicaceae & Seed & 83.2 & 99.3 \\
\hline B. oleracea var. italica & Early purple sprouting & Brassicaceae & Seed & 82 & 97.3 \\
\hline Amaranthus cruentus & Golden Giant & Amaranthaceae & Seed & 66.7 & 95.1 \\
\hline B. juncea & Aurea & Brassicaceae & Seed & 86.5 & 93.9 \\
\hline Aurinia saxatilis & & Brassicaceae & Seed & 72.1 & 93.5 \\
\hline Beta vulgaris & Bison & Amaranthaceae & Seed & 50.9 & 91.9 \\
\hline Beta vulgaris & Sanetta & Amaranthaceae & Seed & 54.1 & 91.4 \\
\hline B. rapa ssp. pekinensis & & Brassicaceae & Seed & 79.9 & 91.4 \\
\hline Beta vulgaris & Ardan & Amaranthaceae & Seed & 57.6 & 87.2 \\
\hline Spinacia oleracea & Géant d'hiver & Amaranthaceae & Seed & 42.4 & 86.8 \\
\hline B. napus & Alpaga & Brassicaceae & Seed & 64.3 & 86.8 \\
\hline Beta vulgaris & Nemata & Amaranthaceae & Seed & 64.6 & 86.2 \\
\hline B. vulgaris ssp. maritima & & Amaranthaceae & Seed & 30 & 85.5 \\
\hline Portulaca oleracea & & Portulaceae & Seed & 56.6 & 84.4 \\
\hline Atriplex hortensis & & Amaranthaceae & Seed & 43 & 83.6 \\
\hline Nasturtium officinale & & Brassicaceae & Seed & 57 & 82.9 \\
\hline S. tuberosum & Désirée & Solanaceae & Tuber & 67 & 82.3 \\
\hline Pisum sativum & James & Fabaceae & Seed & 35 & 82 \\
\hline Chenopodium quinoa & & Amaranthaceae & Seed & 32.3 & 81.9 \\
\hline Pastinaca sativa & Demi Long de Guernesey & Apiaceae & Seed & 47.2 & 79.3 \\
\hline D. carota ssp. sativus & Nantaise & Apiaceae & Seed & 41.1 & 68.5 \\
\hline Dianthus barbatus & Kaléïdoscope & Caryophyllaceae & Seed & 42.1 & 66.6 \\
\hline A. thaliana & & Brassicaceae & Seed & 43.6 & 64.9 \\
\hline S. lycopersicum & "Saint-Pierre" & Solanaceae & Seed & 52.3 & 64.6 \\
\hline Sinapis alba & Cador & Brassicaceae & Seed & 22 & 61.1 \\
\hline Eruca vesicaria ssp. sativa & & Brassicaceae & Seed & 26 & 60.3 \\
\hline Pisum sativum & Lumina & Fabaceae & Seed & 6.3 & 47.6 \\
\hline
\end{tabular}

the mass production of root exudates with satisfactory levels of hatching induction attributes and the ideal conditions for application to obtain optimum levels of hatching for two of the three studied nematode species (G. pallida and H. carotae).

In vitro screening confirmed documented information about the host range of each species. $H$. schachtii exhibited high levels of hatching with the majority of root exudates. This could in part be attributed to its limited dependency on hatching stimulants as this species has a wide host range and also know to hatch readily in water (Perry, 2002). It was further demonstrated in soil experiments that favorable soil conditions (i.e., appropriate temperature and moisture) without host root exudates were sufficient to induce hatching of up to $60 \%$ in H. schachtii. However, hatching factors acted as accelerators in hatching dynamic as after 2 days of exposure, the core plants within its host range such as sugar beet, oil seed rape and other Brassicaceae induced hatching above 50\%. With the observed levels of hatching without the presence of host root exudates, it was deemed not necessary to advice for the incorporation of the 'suicide hatching' strategy in the management of $H$. schachtii. This was because the application of root exudates would not generate substantial gains when compared with natural conditions only or the use of resistant varieties/cultivars or traps in an intercrop.

Unlike $H$. schachtii, the hatching of the carrot cyst nematode $H$. carotae was mainly induced by carrot varieties (Daucus carota). However, the novel findings included five wild relative species that featured within the top ten varieties, inducing high levels of hatching. Plants belonging to other genera outside Daucus were unable of inducing significant levels of hatching as compared with water. These observations are in line with the referenced narrow host range of this nematode species (Aubert, 1986) with a high dependence on chemical cues emitted by the host plant for hatch induction. This reinforced the hypothesis that $H$. carotae had coevolved with wild relative of carrots for a long time in its native area before being adapted to the cultivated varieties (Gautier et al., 2019).

The hatching behavior of G. pallida has been extensively studied (see Perry, 2002; Masler and Perry, 2018 for reviews) and not surprisingly, our screening revealed a strong induction of hatching by solanaceous cultivated plants such as potatoes, tomatoes and eggplants. The top five plants that induced the highest levels of hatching included three European cultivated varieties of potato, one cultivated variety of eggplant and 


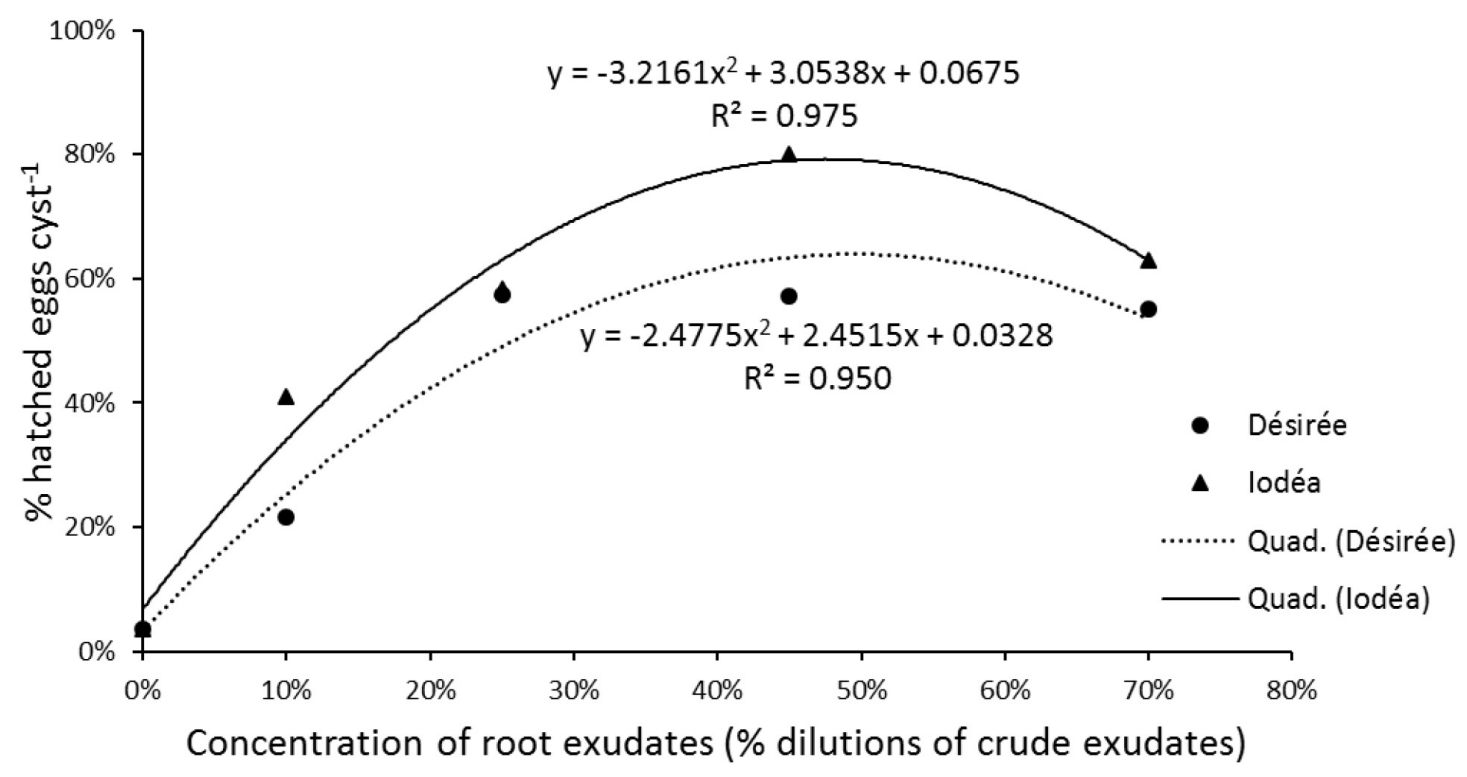

FIGURE 1 | The relationships between in vitro hatching of Globodera pallida and concentration (0, 10, 25, 45, or 70\%) of the crude root exudates of Solanum tuberosum var. Désirée or lodéa. The regression coefficient $\left(R^{2}\right)$ and equations of the quadratic model are indicated for each potato variety. Data points represents means values of six replicates.

TABLE 2 | Percentage hatched eggs cyst ${ }^{-1}$ ( \pm SE) following continuous or periodic exposure for 4 h every 6 days to root exudates over 30 days.

\begin{tabular}{|c|c|c|c|c|c|}
\hline \multirow[t]{2}{*}{ Nematode species } & \multirow[t]{2}{*}{ Root exudate } & \multirow[t]{2}{*}{ Dilutions (\%) } & \multicolumn{3}{|c|}{ Exposure time of cysts with root exudates } \\
\hline & & & $4 \mathrm{~h}$ every 6 days & Continuous exposure & No exposure (water) \\
\hline Globodera pallida & Potato var. Désirée & 30 & $91.9(1.4)^{a}$ & $95.7(0.6)^{a}$ & $14,1(5.9)^{b}$ \\
\hline Heterodera carotae & Carrot cv. Touchon & 30 & $68.3(6.8)^{a}$ & $78.8(5.9)^{a}$ & $1,1(0.9)^{b}$ \\
\hline H. schachtii & Sugar beet cv. Acacia & 85 & $98.2(0,1)$ & $93.2(1.0)$ & $93.9(1.9)$ \\
\hline
\end{tabular}

Data across each raw with similar superscript lower case letters are not statistically different according to Tukey test (5\% level of significance).

also one wild potato from South-America. Nevertheless, the distinction between host and non-host for G. pallida did not appear as clear as for $H$. carotae, with a stable decline from 95\% in hosts to $1 \%$ hatching in non-host species (Table 1A). However, the screening experiment revealed some surprising results with broccoli (Brassica oleracea var. Italica) which induced $56.7 \%$ hatch. This was unexpected as this plant has not previously been listed in G. pallida's host range, and more so, the Brassicaceae are phylogenetically far from Solanaceae. These results raised the questions whether all broccoli varieties have this ability and whether hatching is stimulated at the same level for all populations of G. pallida [i.e., European population and South American populations belonging to the 5 clades described by Picard et al. (2007)]. These results revealed that, it might be possible to identify non-host plants that can induce substantial hatching and that it may be interesting to screen outside the referenced host range for future use as cash and/or trap crops. The identification of specific chemical cues present in broccoli root exudates might help save time usually spent on screening assays. This would facilitate the selection for appropriate cultivated plants and varieties based on their chemical composition as well as to compare the hatching factors present in broccoli root exudates with those present in solanaceous plants.

Following the mass screening, root exudates that produced satisfactory results under in vitro conditions were further assessed for ideal doses and exposure times necessary to induce optimum hatching, before the confirmation of their efficiency in a more complex soil environment. The choice was driven by the ability of the root exudates to induce satisfactory levels of hatching, as well as the ease of production. Two varieties of potatoes, Désirée and Iodéa were therefore selected for potato cyst nematodes, while two varieties of carrots, Touchon and Pusa Kesar were selected for carrot cyst nematode, $H$. carotae and two sugar beet varieties, Julietta and Acacia were retained for H. schachtii.

In vitro experiments demonstrated that simulating the presence of the host plant by exposing $H$. carotae or G. pallida to their respective host root exudates at very low concentration or for very short and repeated periods induced significant hatching as compared with water control. These observations are in line with previous reports, which demonstrated that hatching factors were able to induce substantial levels of hatching in cyst nematodes at very low concentration (Masler and Perry, 2018) and that a brief exposure may as well induce similar levels of 


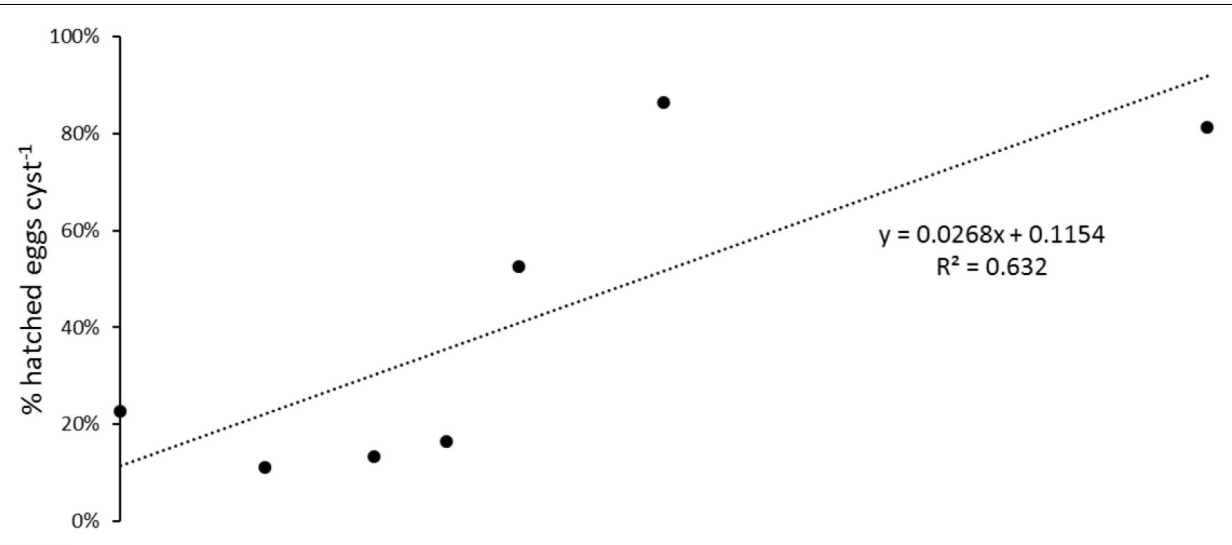

A
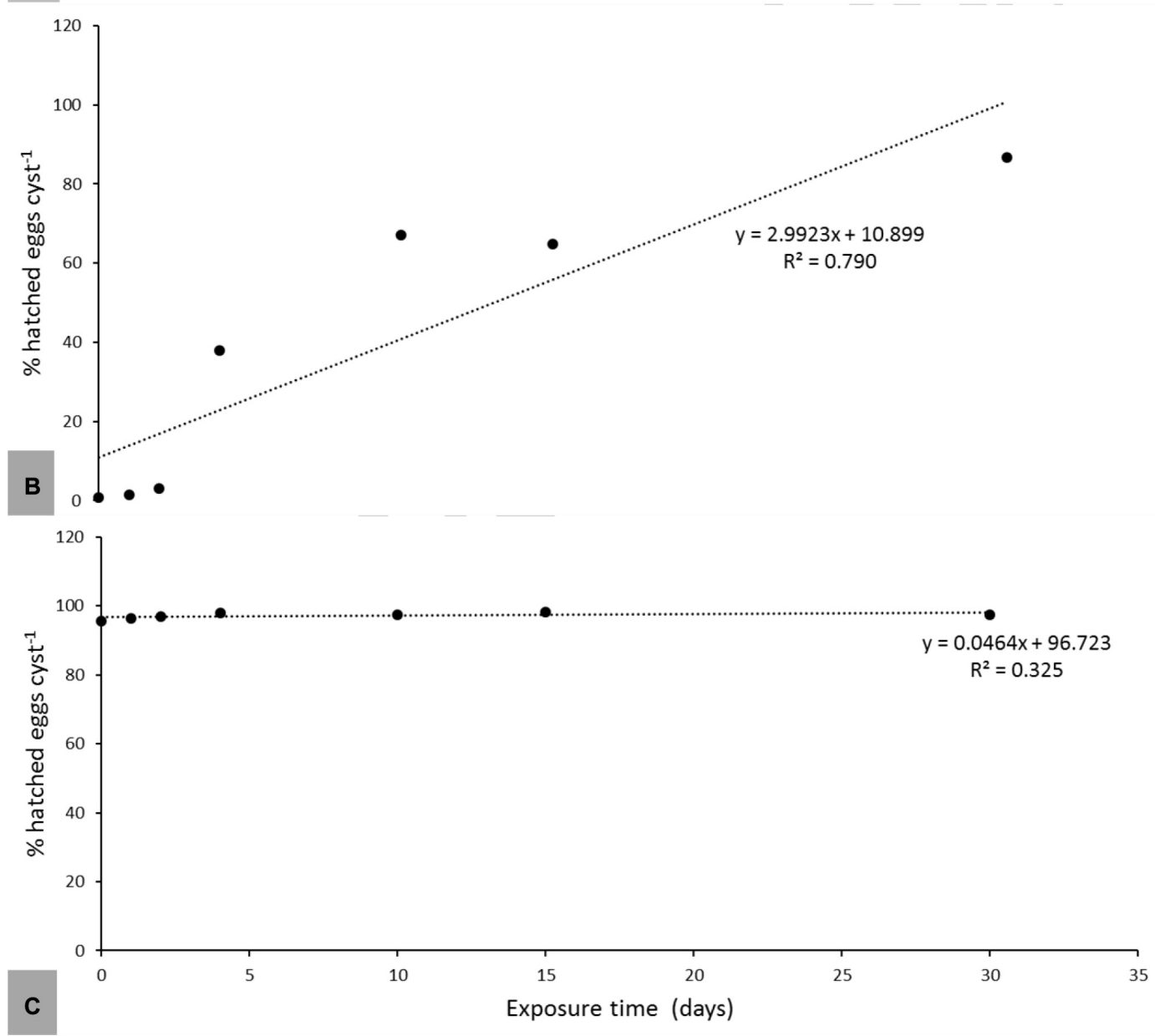

FIGURE 2 | The relationships between in vitro hatching of G. pallida (A), H. carotae (B), and $H$. schachtii (C) and exposure time to root exudates of Solanum tuberosum var. Désirée, Daucus carota cv. Touchon and Beta vulgaris cv. Acacia at $45 \%$ dilution, respectively. The regression coefficient $\left(R^{2}\right)$ and equations of the linear model are indicated for each potato variety. Data points represents means values of six replicates.

hatching as a continuous exposure. There exist sufficient evidence of the hatching behavior for G. pallida (Perry and Beane, 1982; Perry, 2002), but little information was available on the hatching behavior of $H$. carotae. An average exposure time of 15 days to root exudates was necessary to induce satisfactory levels of hatching for both $\mathrm{H}$. carotae and G. pallida with approximately over 60 and $80 \%$ hatched juveniles, respectively. For G. pallida, the level of hatching was comparable with hatching observed in continuous exposure to root exudates. This confirmed previous observations where $80 \%$ of encysted J2 hatched within 12 days 
TABLE 3 | Characteristics of the soils used in the pot experiments with the respective sites where the soils were collected.

\begin{tabular}{|c|c|c|c|c|c|c|c|}
\hline Soil origin & Texture & Clay (\%) & Fine silt (\%) & Coarse silt (\%) & Fine sand (\%) & Coarse sand $(\%)$ & $\mathrm{pH}$ \\
\hline Laon, France & Sandy-soil & 10,1 & 6,6 & 10,6 & 65,6 & 7,1 & 7,9 \\
\hline La Gruche, France & Silty-sand & 8,5 & 12,8 & 26 & 8,1 & 44,6 & 6,9 \\
\hline Gatteville-le-Phare, France & Sandy-clay & 13,4 & 11,9 & 10,5 & 34,3 & 29,9 & 6,8 \\
\hline
\end{tabular}

Data across each raw with similar superscript lower case letters are not statistically different according to Tukey test (5\% level of significance).

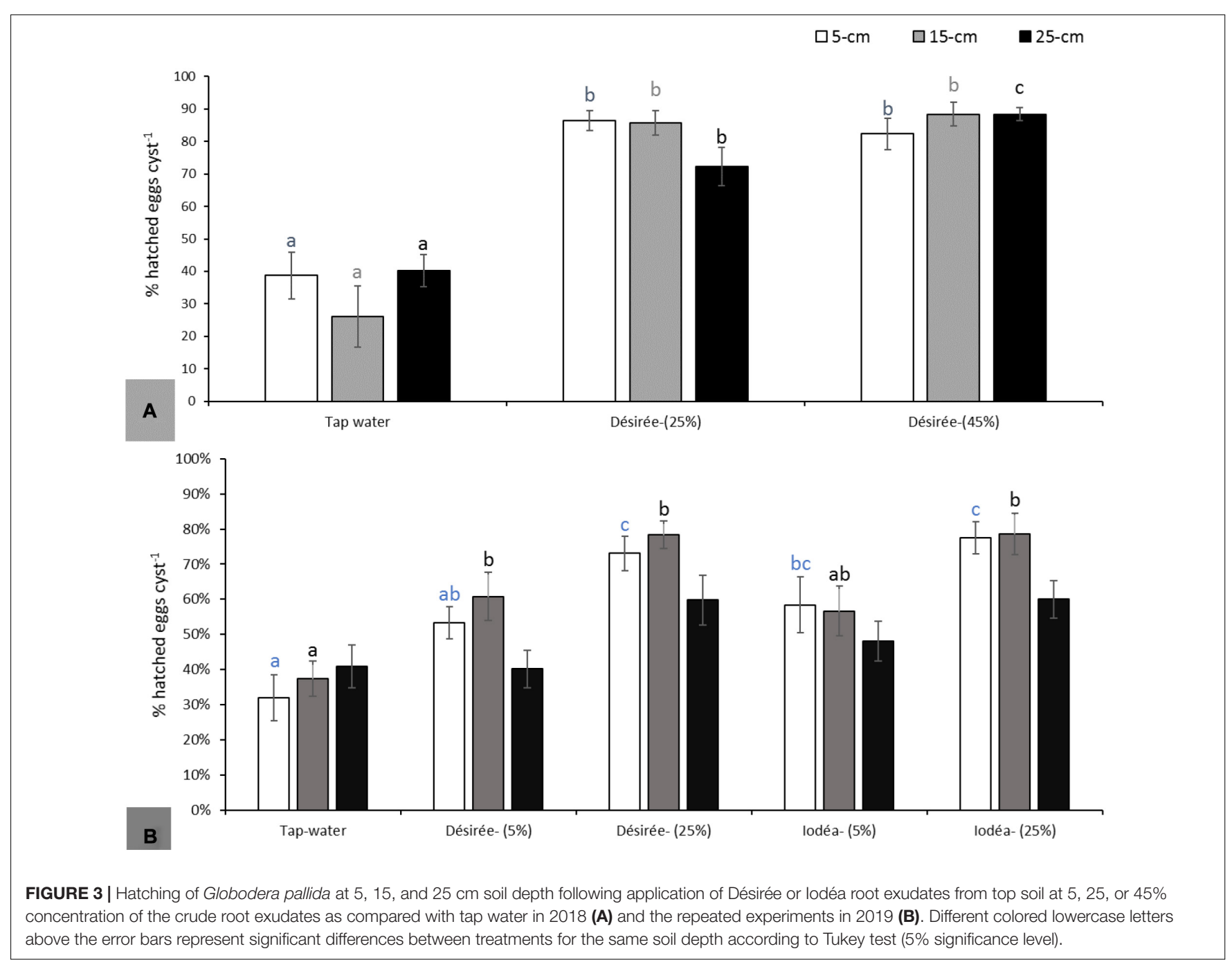

of exposure (Masler et al., 2008a,b), which is an adaptation by infective juveniles to maximize their chance for successful infection of young healthy roots of the host plant (LaMondia and Brodie, 1984). It was also observed that brief exposure to root exudates for $6 \mathrm{~h}$ every 4 days was able to stimulate similar level of hatching as in continuous exposure. The dilution of potato root exudates to concentrations as low as $10 \%$ of the crude root exudates induced satisfactory levels of hatching, which was not significantly different from hatching in root exudates diluted to $25 \%$. Preliminary experiments conducted on $H$. carotae exhibited similar hatching behavior (data not shown), suggesting that the high sensitivity to hatching factors, coupled with the high specificity were probably shared traits between species that had a narrow host range, such as $H$. carotae and $G$. pallida.
As a follow-up from in vitro studies, it was necessary to assess the performance of the root exudates in a more complex soil environment, much closer to field conditions. Therefore, treatments for the pot experiments were based on observations from in vitro tests. Observations on $H$. schachtii revealed only a slight increase in hatching percent for treatment with root exudate as compared with water, confirming in vitro observations. On the contrary, $H$. carotae and G. pallida responded better to host root exudates as compared with water, depending on the soil depth and on the applied dose of the root exudates. Generally, hatching is optimized at soil moisture equivalent to field capacity and favorable temperatures (Masler and Perry, 2018) which matches the conditions employed in the present study (within $60-80 \%$ of field capacity, at $14-20^{\circ} \mathrm{C}$ ). 

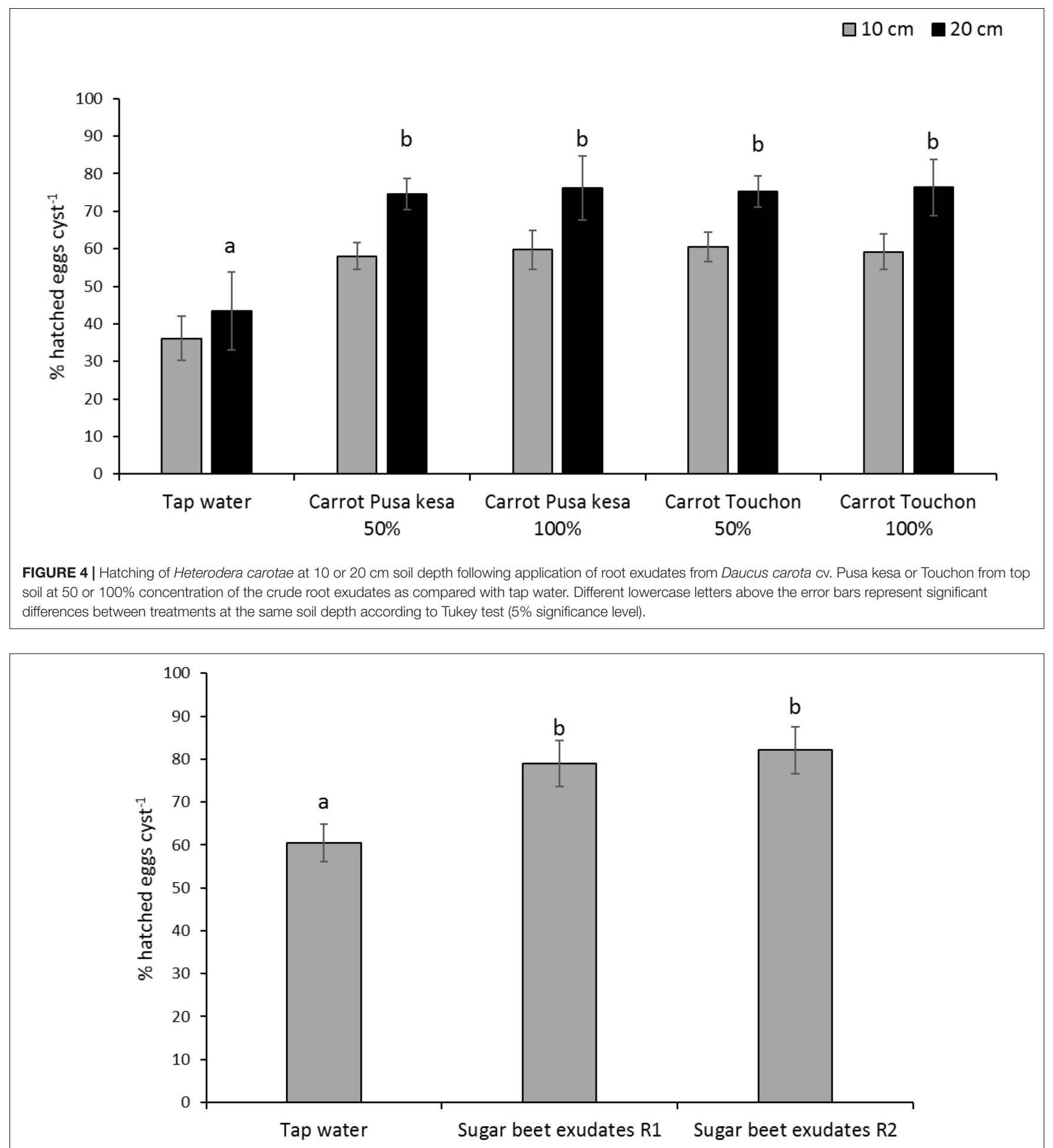

FIGURE 5 | Hatching of Heterodera schachtii at $4 \mathrm{~cm}$ soil depth following application of $15 \mathrm{or} 30 \mathrm{ml}$ root exudates of sugar beet from top soil at $100 \%$ concentration at 2 (R1) or 4 (R2) days intervals, respectively, as compared with tap water as controls. Different lowercase letters above the error bars represent significant differences between treatments according to Tukey test (5\% significance level).

There was a significant dose effect for Iodéa root exudates on G. pallida, but not for Désirée root exudates. Likewise, concentration was not an important factor for H. carotae under soil conditions. For G. pallida, hatching was often greater within the top $15 \mathrm{~cm}$ of soil than at $25 \mathrm{~cm}$ depth, except at $45 \%$ concentration in which the level of hatching was identical 
between the three soil depths investigated. The low hatch observed at $25 \mathrm{~cm}$ depth meant either that the root exudates did not reach the $25 \mathrm{~cm}$ level or that the quantity that attained this level was insufficient to stimulate the levels of hatch observed within the top $15 \mathrm{~cm}$ soil depth. These observations are in line with those of Ryan and Devine (2005) who demonstrated a progressive increase in PCN hatch over a period of 8 weeks postplanting, depending on the distance at which encysted eggs were incubated from the host plant. Earlier report by Rawsthorne and Brodie (1987) also demonstrated that root exudates produced near the root tip were biologically more active in hatching induction. However, unlike G. pallida, hatching was enhanced for $H$. carotae cysts incubated at $20 \mathrm{~cm}$ than for cysts incubated at $10 \mathrm{~cm}$ soil depth, with no observed dose effect.

From the present study, useful information could be drawn for future use of the 'suicide hatching' strategy for application on a field scale to control populations of G. pallida and H. carotae. This would involve the application of host root exudates: (i) in the absence of host crops, (ii) at a period where abiotic conditions will be favorable to hatching, (iii) at different intervals within the first 15 days or using a slow diffusion process (for granular forms) to stimulate encysted eggs to ensure optimum hatching and (iv) at a dose that allowed the induction of hatching within the vicinity of soil where cysts are usually detected (top $30 \mathrm{~cm}$ ). These results would complement previous studies to address different challenges and select best practices. Devine and Jones (2001) investigated the effect of exogenously applied root exudates on hatching and in-egg mortality under field conditions, and although the effect of soil depth was not taken into account, the soil was rotavated following root exudates application to ensure their uniform distribution within the targeted soil profiles. Been and Schomaker (2013) reported approximately $90 \%$ of the PCN population within the upper $35 \mathrm{~cm}$ of soil in an infested field, while sampling at $25 \mathrm{~cm}$ was more uniform and represented approximately $84 \%$ of PCN population. Whitehead (1977) reported similar results for the vertical distribution of PCN, beet and pea cyst nematodes, although pea cyst nematodes were rarely found beyond $20 \mathrm{~cm}$ soil depth. The respective depth reported for each group of nematodes represents the vicinity within which the majority of host roots reside within the planting ridge. Under natural conditions, factors such as soil temperature, moisture, $\mathrm{pH}$, organic matter content all influence the activity of hatching related compounds as well as the response of cyst nematodes to hatching chemicals (see Masler and Perry, 2018 for a review). Hatching activity induced by exogenously applied root exudates have previously been demonstrated to respond best and faster in sandy soils when compared with clay and peaty soils under field conditions (Devine and Jones, 2001). Poor results in peaty soils may in part be associated with possible sorption of hatching chemicals to organic matter, as negative correlations

\section{REFERENCES}

Aubert, V. (1986). "Hatching of the carrot cyst nematodes," in Cyst Nematodes, eds F. Lamberti and C. E. Taylor (New York, NY: Plenum Press), 347-348. doi: 10.1007/978-1-4613-2251-1_26 have previously been reported between organic matter content and hatch factors activity (Devine et al., 2001). In the present study, sandy soils were used for all groups of nematodes, and gave satisfactory results.

In addition to the influence of these parameters, major challenges will be (i) to ensure that soil biological communities have no impact on efficiency of hatching factors, or if it will have to be consider by adjusting the doses for instance, and (ii) to chemically identify hatching factors for both species for mass production and at a lower cost which would compensate for deregistered chemicals previously used in controlling these groups of cyst nematodes. Field validation of these observations are now needed.

\section{DATA AVAILABILITY STATEMENT}

The raw data supporting the conclusions of this article will be made available by the authors, without undue reservation.

\section{AUTHOR CONTRIBUTIONS}

All experimental protocols were jointly discussed and developed by the CMI, FN3PT/inov3PT, INRAE, and SILEBAN scientific and technical team. BN, MI, and PD established and assessed the laboratory and glasshouse experiments involving Globodera pallida conducted at FN3PT/inov3PT, and supervised by VG, $\mathrm{AB}$, and A-CLR. NM, M-CD, CaP, and ChP established and assessed the laboratory and glasshouse experiments involving Globodera pallida and Heterodera schachtii conducted at IGEPP, and supervised by JM and SF. ER and AC established and assessed the laboratory and glasshouse experiments involving Heterodera carotae conducted at SILEBAN. Host root exudates for potato and beet cyst nematodes were produced at FN3PT/inov3PT, and IGEPP, respectively. Carrot root exudate production was jointly developed by SILEBAN and CMI, performed at SILEBAN, and supervised by ER and AC. Root exudate analyses was done at CIM Groupe-Roullier and coordinated by EN-O and J-CY, who also supervised the analysis for soil particle size distribution for the soils used in glasshouse experiments. All authors contributed to the article and approved the submitted version.

\section{FUNDING}

This work was funded by ADEME (Agence de l'Environnement et de la Maîtrise de l'Energie) through the French "Programme Investissement d'Avenir" (PIA) BIODERA Project $\left(n^{\circ}: 1682\right.$ C0289) which was coordinated by the Centre Mondial de l'Innovation - Roullier.

Bairwa, A., Venkatasalam, E. P., Umamaheswari, R., Sudha, R., and Singh, B. P. (2017). Effect of cultural practices on potato cyst nematode population dynamics and potato tuber yield. Indian J. Hortic. 74, 91-96. doi: 10.5958/0974-0112.2017. 00021.4 
Been, T. H., and Schomaker, C. H. (2013). "Distribution patterns and sampling," in Plant Nematology, 2nd Edn, eds R. N. Perry and M. Moens (Wallingford: CAB International), 331-358. doi: 10.1079/9781780641515.0331

Chen, S. Y., Porter, P. M., Orf, J. H., Reese, C. D., Stienstra, W. C., Young, N. D., et al. (2001). Soybean cyst nematode population development and associated soybean yields of resistant and susceptible cultivars in Minnesota. Plant Dis. 85, 760-766. doi: 10.1094/PDIS.2001.85.7.760

Devine, K. J., Byrne, J., and Jones, P. W. (2001). In vitro studies on the relative availability and mobility in soil of natural hatching factors for the potato cyst nematodes, Globodera rostochiensis and G. pallida. Nematology 3, 75-83. doi: $10.1163 / 156854101300106919$

Devine, K. J., and Jones, P. W. (2000). Response of Globodera rostochiensis to exogenously applied hatching factors in soil. Ann. Appl. Biol. 137, 21-29. doi: 10.1111/j.1744-7348.2000.tb00053.x

Devine, K. J., and Jones, P. W. (2001). Effects of hatching factors on potato cyst nematode hatch and in-egg mortality in soil and in vitro. Nematology 3, 65-74. doi: $10.1163 / 156854101300106900$

Evans, K. (1983). Hatching of potato cyst nematodes in root diffusates collected from 25 potato cultivars. Crop Protection 2, 97-103. doi: 10.1016/02612194(83)90029-7

Evans, K., and Stone, A. (1977). A review of the distribution and biology of the potato cyst-nematodes Globodera rostochiensis and G. pallida. PANS 23, 178-189. doi: 10.1080/09670877709412426

Franco, J., Main, G., and Oros, R. (1999). Trap crops as a component for the integrated management of Globodera spp. (potato cyst nematodes) in Bolivia. Nematropica 29, 51-60.

Fukuzawa, A., Furusaki, A., Ikura, M., and Masamune, T. (1985a). Glycinoeclepin A, a natural hatching stimulant for the soybean cyst nematode. J. Chem. Soc. 4, 222-224. doi: 10.1039/c39850000222

Fukuzawa, A., Matsue, H., Ikura, M., and Masamune, R. (1985b). Glycinoeclepins B and C, nortriterpenes related to glycinoeclepin A. Tetrahedron Lett. 26, 5539-5542. doi: 10.1016/s0040-4039(01)80882-0

Gautier, C., Esquibet, M., Fournet, S., Piriou, C., Yvin, J. C., Nguema-Ona, E., et al. (2019). Microsatellite markers reveal two genetic groups in European populations of the carrot cyst nematode Heterodera carotae. Infection Genet. Evol. 73, 81-92. doi: 10.1016/j.meegid.2019.04.011

Johnson, J. B., and Omland, K. S. (2004). Model selection in ecology and evolution. Trends Ecol. Evol. 19, 101-108. doi: 10.1016/j.tree.2003.10.013

Jones, T. J., Annelies, H., Etienne, G. J. D., Hari, S. G., Johannes, H., Michael, G. K. J., et al. (2013). Top 10 plant-parasitic nematodes in molecular plant pathology. Mol. Plant Pathol. 14, 946-961. doi: 10.1111/mpp.12057

Kushida, A., Suwa, N., Ueda, Y., and Momota, Y. (2003). Effects of Crotalaria juncea and C. spectabilis on hatching and population density of the soybean cyst nematode, Heterodera glycines (Tylenchida: Heteroderidae). Appl. Entomol. Zool. 38, 393-399. doi: 10.1303/aez.2003.393

LaMondia, J. A., and Brodie, B. B. (1984). Control of Globodera rostochiensis by solar heat. Plant Dis. 68, 474-476. doi: 10.1094/PD-69-474

Marks, R. J., and Brodie, B. B. (1998). Potato Cyst Nematodes: Biology, Distribution and Control. Wallingford: $\mathrm{CAB}$ International.

Masamune, T., Anetai, M., Takasugi, M., and Katsui, N. (1982). Isolation of a natural hatching stimulus, glycinoeclepin A, for the soybean cyst nematode. Nature 297, 495-496. doi: 10.1038/297495a0

Masler, E. P., Donald, P. A., and Sardanelli, S. (2008a). Stability of Heterodera glycines (Tylenchida: Heteroderidae) juvenile hatching from eggs obtained from different sources of soybean, Glycine max. Nematology 10, 271-278. doi: 10. $1163 / 156854108783476322$

Masler, E. P., and Perry, R. N. (2018). Hatch, Survival and Sensory Perception. Cyst Nematodes. Oxforshire: CAB International, 44-73.

Masler, E. P., Zasada, I. A., and Sardanelli, S. S. (2008b). Hatching behavior in Heterodera glycines in response to low temperature. Comp. Parasitol. 75, 76-81. doi: $10.1654 / 4292.1$
Mugniéry, D., and Bossis, M. (1988). Heterodera carotae Jones, (1950). Gamme d'hôtes, vitesse de développement, cycle. Rev. Nématol. 11, 307-313.

Ngala, B. M., Haydock, P. J., Wood, S., and Back, M. A. (2014). ). Biofumigation with Brassica juncea, Raphanus sativus and Eruca sativa fort the management of field populations of the potato cyst nematode Globodera pallida. Pest Manage. Sci. 71, 759-769. doi: 10.1002/ps.3849

Nicol, J. M., Turner, S. J., Coyne, D. L., den Nijs, L., Hockland, S., and Maafi, Z. T. (2011). "Current nematode threats to world agriculture," in Genomics and Molecular Genetics of Plant-Nematode Interactions, eds J. Jones, G. Gheysen, and C. Fenoll (Dordrecht: Springer), 21-43. doi: 10.1007/978-94-0070434-3_2

Perry, R. (2002). "Hatching," in The Biology of Nematodes, ed. D. L. Lee (Abingdon: Taylor \& Francis), 147-170.

Perry, R. N., and Beane, J. (1982). The effect of brief exposures to potato root difusate on the hatching of Globodera rostochiensis. Rev. Nematol. 5, 221-224.

Picard, D., Sempere, T., and Plantard, O. (2007). A northward colonisation of the Andes by the potato cyst nematode during geological times suggests multiple host-shifts from wild to cultivated potatoes. Mol. Phylogenet. Evol. 42, 308-316. doi: 10.1016/j.ympev.2006.06.018

Rawsthorne, D., and Brodie, B. B. (1987). Movement of potato root diffusate through the soil. J. Nematol. 19, 119-122.

Robinson, M., Atkinson, H., and Perry, R. (1987). The influence of temperature on the hatching activity and lipid utilization of second stage juveniles of the potato cyst nematodes Globodera rostochiensis and G. pallida. Rev. Nematol. 10, 349-354.

Ryan, A., and Devine, K. J. (2005). Comparison of the in-soil hatching responses of Globodera rostochiensis and G. pallida in the presence and absence of the host potato crop cv. British Queen. Nematology 7, 587-597. doi: 10.1163/ 156854105774384804

Scholte, K. (2000). Screening of non-tuber bearing Solanaceae for resistance to and induction of juvenile hatch of potato cyst nematodes and their potential for trap cropping. Ann. Appl. Biol. 136, 239-246. doi: 10.1111/j.1744-7348.2000. tb00030.x

Storey, R. M. J. (1984). The relationship between neutral lipid reserves and infectivity for hatched and dormant juveniles of Globodera spp. Ann. Appl. Biol. 104, 511-520. doi: 10.1111/j.1744-7348.1984.tb0 3034.x

Subbotin, S. A., Mundo-Ocampo, M., and Baldwin, J. G. (2010). "Systematics of cyst nematodes (Nematoda: Heteroderinae)," in Nematology Monographs and Perspectives 8 A Series, eds D. J. Hunt and R. N. Perry (Leiden: Brill).

Turner, S. J., and Subbotin, S. A. (2013). "Cyst nematodes," in Plant Nematology, 2nd Edn, eds R. N. Perry and M. Moens (Wallingford: CAB International), 109-143.

Whitehead, A. G. (1977). Vertical distribution of potato, beet and pea cyst nematodes in some heavily infested soils. Plant Pathol. 26, 85-90. doi: 10.1111/ j.1365-3059.1977.tb01029.x

Widdowson, E., and Wiltshire, G. H. (1958). The potato eelworm hatching factor. Ann. Appl. Biol. 46, 95-101. doi: 10.1111/j.1744-7348.1958.tb02181.x

Conflict of Interest: The authors declare that the research was conducted in the absence of any commercial or financial relationships that could be construed as a potential conflict of interest.

Copyright (c) 2021 Ngala, Mariette, Ianszen, Dewaegeneire, Denis, Porte, Piriou, Robilliard, Couetil, Nguema-Ona, Yvin, Gobert, Beury, Le Roux, Montarry and Fournet. This is an open-access article distributed under the terms of the Creative Commons Attribution License (CC BY). The use, distribution or reproduction in other forums is permitted, provided the original author(s) and the copyright owner(s) are credited and that the original publication in this journal is cited, in accordance with accepted academic practice. No use, distribution or reproduction is permitted which does not comply with these terms. 